Article

\title{
Communication Barrier, Spillover Effect and Industrial-Technological Innovation
}

\author{
Jin Guo ${ }^{1} \oplus$, Bingmei Gu ${ }^{2}$, Xialing Sun ${ }^{3}$, Jinli Xue ${ }^{4, *}$ and Baiyun Yuan ${ }^{4, *}$ \\ 1 School of Surveying and Land Information Engineering, Henan Polytechnic University, \\ Jiaozuo 454000, China \\ 2 School of Management, Shanghai University, Shanghai 200444, China \\ 3 School of Management, China University of Mining and Technology, Beijing 100083, China \\ 4 Research Center for Energy Economics, School of Business Administration, Henan Polytechnic University, \\ Jiaozuo 454000, China \\ * Correspondence: xuejinli@hpu.edu.cn (J.X.); yuanbaiyun@hpu.edu.cn (B.Y.)
}

Received: 8 July 2019; Accepted: 26 August 2019; Published: 5 September 2019

check for updates

\begin{abstract}
Industrial-technological innovation (ITI) has far-reaching significance for China's sustainable development. In this study, we construct an ITI model to analyze the impact of communication barrier and spillover effects in ITI system from the perspective of system by means of system dynamics. Statistical data of smartphone industry were collected to verify the authenticity of the model, which show that the model has higher goodness of fit with the real-world. Simulation experiments were carried out and the results showed that: (1) Spillover effects have obvious effects on ITI in both positive and negative radiation directions, and deeper exchanges and cooperation should be encouraged to carry out among firm. (2) Communication barrier play an important role in regulating ITI. Under the condition of non-barrier and complete-barrier, the completion time of the whole process has increased by $76.5 \%$, it is urgent to reduce communication carrier. The research puts forward suggestions to help improve ITI from institutional, market, and government.
\end{abstract}

Keywords: industrial-technological innovation; communication barrier; spillover effect; system dynamics

\section{Introduction}

Various factors lead to the slowdown of China's economic growth [1]. It is not only affected by the international economic downturn but also due to the imbalance of China's domestic industrial structure [2,3].The imbalanced industrial structure in China can be observed in many aspects. For example, the overcapacity in China's energy-intensive industries; lagging behind in high-tech industries; weak service for consumer's needs, etc. [4]. It is worth mentioning that the low level of industrial technology is one of the reasons [5]. The development model of China's low-edge manufacturing industry which relied on importing and imitating other countries' technology has been unsustainable [6]. "Made in China 2025" plan once again provides that the driving force of high-tech and innovation is an important support for China's sustainable development [7]. Changing the mode of economic growth and industrial-technological innovation (ITI) is related to the "middle-income trap" and the existing social contradictions in China, which is a major challenge for its future development [8].

In order to overcome Chinese major challenge, the government has launched two major strategies, "The Belt and Road Initiative" [9] and "Innovating China" [10], which aim at win-win cooperation and innovative development in China's industries [2]. Under the open environment, the communication between innovation subjects is becoming more frequent, and the path of cooperation affecting innovation has gradually become an academic hot issue [11]. Technology communication and spillover are the main ways of ITI [5,12]. However, no consensus has been reached on the effects between technology 
communication and spillover, and there are still great disputes on the mechanism and influence mode. In the framework of ITI, it is noteworthy to mention that the influence mode, degree of communication barrier and spillover should be solved quickly. In this study, we focus on ITI model and try to explain three main questions:

1. How to divide the process of ITI?

2. What factors can influence ITI?

3. How does the communication barrier (CB) and spillover effect (SE) affect ITI?

To the best of our knowledge, we highlight our contributions in the following, and the main contributions of this research can be described as the following three aspects. Firstly, it expands the scope of research on ITI, not only examines the path of ITI from a systematic perspective but also studies the relationship of the influencing factors, which has important reference value for understanding the path of ITI. Secondly, it deepens the research of ITI. Based on the previous researches, it will study the impacts about the differences of communication barrier and spillover effect on ITI from a systematic perspective, which will to supplement the research framework of ITI. Thirdly, it provides a theoretical basis for policymakers, which can help the promotion of ITI.

\section{Literature Review}

For a long time, the nature of technology communication and spillover effect has puzzled many scholars. According to Grupp [13], he analyzed data from the European Patent Office by using statistical method, and found that the property of scientific "public goods" was the main cause of the technology communication and spillover. Since then, a lot of research has been done on the relationship between technology communication and spillover effect and innovation. They are mainly reflected in two aspects: first, spillover effect between the same types of subjects (firm to firm, etc.); second, communication and cooperation between different types of subjects (firm to universities, etc.).

First of all, some scholars discussed the relationship between spillover effect and innovation on the same type of subjects. The relationship between multi-level communication and innovation among regions has been a popular research topic for decades. Such as Srholec [14], based on analyzing the micro survey data and macro national data, a big difference between the communication and cooperation of different countries and the domestic was explored, which is mainly caused by the quality of domestic cooperators. Moreover, Liu [15] took Chinese high-tech firm as the research object, researching the spillover effect of multinational firm in host, it is found that high-tech acceptance level is helpful to improve the technology of high-tech firm, but firm development also needs strong innovation ability. Similarly, Liu [2] also came to a similar conclusion. From the viewpoint of Benjamin [16], it is certain that both formal and informal associations can adjust the core management ability through spillover effect, and then exert a positive effect on innovation ability.

After exploring regions and countries, scholars began to study the role of spillovers effect in industries with no obvious physical boundaries. As previously mentioned, Stejskal [17] took the Czech industrial system as an example and conducted analysis based on survey data, and found that more active cooperation between firms would generate a greater driving force for innovation. At the same time, after analyzing the new energy industry in Rwanda, Tigabu [18] found the lack of effective innovation system to support technology diffusion is the main factor behind the new energy technology. In addition, Song [19] built a model which showed the influence from technology transfer to innovation spillover effect, using 2000-2016 date of China industry, and the result showed that: adaptive ripening has positive effect on innovation spillover effect of China industry.

With the development of globalization, the international cooperation of small-sized firms gradually increases, Radicic [20] firstly demonstrated the research on cooperation between small-sized firms: technological (product and process) innovations, non-technological (organizational and marketing) innovations and process innovations (innovative sales), which has obvious complementary effect, and the spillover from couple of cooperations has significantly increased the spread of innovation. 
Another key framework within relationship between technology communication and spillover effect and innovation the different types of subjects (firm, universities, etc.). A lot of work has been done. First, some scholars focus on the impact of university-firm combination on innovation: Kang [21] put forward that different types of subjects were recognized as an effective tool for technological innovation, and broke down the communication barrier effectively. As what Nave [22] argued, if we use university-firm cooperation as a way to promote sustainability practices, according to the information provided by the interview, the university-firm cooperation is more conducive for firm to solve their own problems through innovation.

After studied of university-firm cooperation, some scholars pay attention to the key factors of cooperation between university and firm. Considering the perspective determinants of university-firm cooperation, Diego [23] has argued that internal characteristics of firm (size etc.), and external characteristics of markets and policies (economic risk etc.) were the major factor of that. Wang [24] proposes that university and firm should further reduce the distance, both geographically and organizationally, because closer relationships (space or organizational) will help increase communication and innovation.

Throughout all the literature, the research system of ITI with communication barrier and spillover effect has been basically established, but there are still deficiencies in research methods and contents.

In terms of research content, current research is mainly based on the impact of a single factor on ITI. There are few studies on the communication barrier and spillover effects under the effect of system feedback regulation. In view of this, this study will depict ITI from a system perspective, analyze the feedback regulating effect among various factors, especially the system development law under extreme value conditions, and then explore the role of communication barrier and spillover effects in the process of ITI.

In terms of research methods, Empirical research is the main research method, which not only fails to systematically depict the relationship between the process of ITI improvement and various influencing factors but also fails to take into account the interaction between various factors. In addition, such as excessive reliance on real data, and lack of research on the impact of extreme values. As argued by many experts, the process of ITI is affected by many factors and the relationship between them is highly complex. So, traditional methods have many limitations in dealing with complex large-scale systems. Therefore, it is necessary to apply more suitable methods to study the path of ITI.

System-Dynamics (SD), a method for studying highly complex system, which is supported by system feedback theory and computer simulation. SD has great advantages in dealing with the problems of complex system with nonlinearity, high complexity, multi-level and multi-feedback [25]. On the one hand, SD theoretical modeling is carried out based on taking full account of the feedback loop inside the system, and the influence of the dynamic changes of each factor is analyzed; on the other hand, it can be explored the extreme historical data. SD model has been widely used in Social-Sciences [26,27] and Natural-Sciences $[28,29]$. It is a mature method to solve complex system problems.

\section{Model Development}

\subsection{The Theoretical Background Analysis}

The ITI is a complex system with a long span and many participating factors. How to divide the process of ITI is a key issue. Tunzelmann et al. [30] are the pioneer to study the process of industrial technology. Industrial technology is regarded as the process of integrating and learning different knowledge structures and integrating knowledge into new products. Soon afterwards, Tunzelmann et al. [31] improved by proposing that industrial technology was a means to improve product quality and service efficiency, by introducing new processes and technologies.

The difference between industrial technology and firm technology is the difference in research scope [32]. The research scope of industrial technology is more abundant when studying industrial technology, while the scope of firm technology is relatively narrow, mainly focuses on the study 
of a single firm. Because an industry consists of enormous firms with the same nature (business scope, firm attributes, operation mode, etc.). There is a similar relationship between this industry technology and firm technology. Industrial technology is a systematic, large-scale and universal firm technology [33,34]. It can only be called industrial technology after it is applied by the vast number of firm in the industry. Therefore, it can be considered that industrial technology innovation is a phenomenon of diffusion between industries after carrying out technological innovation activities. The process of ITI can be divided into "innovation generation" and "innovation diffusion", which is laboratory technological innovation(LTI)and industrialized technological innovation (IDTI).

\subsubsection{Analysis of LTI}

Laboratory technology innovation (LTI) refers to create a new one, that is "innovation generation". Nowadays, the research on the impact of "innovation generation" mainly focuses on the breakthroughs of university, policy or subjectivity differences on innovation.

Scholars firstly pay attention to the impact of Universities on innovation. Juan [35] and Broekel [36] found that higher education also plays an important role in the process of innovation, and universities and innovation ability have an obvious direct or indirect correlation. Hojin [37] studies the impact of Technological Exploration on industrial technology development from the perspective of demand. He believes that technological exploration mainly comes from the university's technological research and market customers' needs. Maria [38] and Fang [39] respectively analyzed the Italian and Chinese samples and reached a highly consistent conclusion that research departments such as universities, geographical location, and firm size are the determinants of Italian firm' technological innovation, while the degree of industrial technology and economic development is highly consistent in space. The innovation level and innovation level of central cities are also significantly higher than those of small and medium-sized cities and the industrial technology level of basic education, economic development and scientific research investment in developed areas has increased significantly.

Subsequently, scholars have done a lot of work from the perspective of regional policy. Kleoniki [40] further confirmed that the innovation efficiency of regions with higher resource utilization efficiency (employment rate, technological diversity, etc.) is higher than that of regions with lower resource utilization efficiency. He also confirmed that the innovation efficiency of regions with underdeveloped and transitional periods is higher, and the innovation efficiency of regions with differentiation and decentralization is higher. The policy of industrialization will provide more clear help to innovation in developed areas, that is, government intervention will have a significant impact on the evolution path of innovation. Miao [41] found that latecomers can learn through various channels to catch up with or even surpass existing firm, and use various government policies to help them start the next generation of research and build development platforms as soon as possible to overcome their initial weaknesses and complete technological catching-up. Rieu [42] argues that the triple helix structure of "government-industry-university" can no longer fully release the scientific and technological innovation of scientific research institutions. It also need to release innovation output and improve the quality of innovation by means of social and regional factors.

Finally, the subjectivity differences also attracted the attention of scholars, and then some scholars carried out research on the relationship between firm differences and innovation. Stav [43] proved that diversified knowledge and differentiated national knowledge have a positive correlation with industrial technological innovation. The reason for this phenomenon is the external positive effect of open knowledge convergence on innovation. Lee [44] found that there is an inverted U-shaped relationship between firm size and industrial technology R\&D intensity, and technology controllability has a significant impact on industrial technology and has produced in different industries. The effect is different, and the technology controllability has obvious regulating effect in the developing stage and the underdeveloped stage.

From this, the LTI is driven by the willingness to upgrade laboratory technology. There are four motivations for the willingness to upgrade laboratory technology: market demand, technological 
breakthroughs in scientific research institutions, controllability of laboratory technology and sense of firm crisis $[36,37,43,44]$. Among them, market demand refers to the customers' demand for the function, application, material or other elements of a certain product in a certain period. Some firm meet the needs of some customers after technological innovation, so the market demand will decrease with time. Technological breakthroughs in scientific research institutions and controllability of laboratory techniques are also key factors. If the scientific research breakthrough ability is strong, it will directly enhance the willingness of the firm to upgrade laboratory technology. Technological controllability can be understood as the probability of completion of laboratory innovation. Higher controllability will lead to greater research and development willingness. Firm crisis sense is generated by firm environmental factors, and the proportion of different types of firm will affect firm continue to affect firm crisis sense. The above motivations together drive the willingness of LTI. The higher willingness means the higher rates of innovation.

\subsubsection{Analysis of IDTI}

The process of IDTI is similar to "point-to-plane", which means the expansion of laboratory innovation, the main results that influence innovation diffusion focus on the study of social network effects. Wang [45] was an early scholar who studied the diffusion of innovation. He used mathematical methods to establish an evolutionary game model. The conclusion shows that knowledge sharing will promote the innovation cluster, which proves that the propagation of innovation in the enterprise network can stimulate industrial innovation. After proving in theory, many scholars have carried out empirical research on the impact of social networks on innovation.

Firstly, Martin [46] draws a conclusion from the organizational perspective of start-ups that industrial models such as inter-departmental linkages and organizational structure of start-ups will affect the industrial capabilities of start-ups, and that different organizational networks will result in differentiated organizational communication multipliers. Subsequently, Zhou [47] firstly proved that firm cooperation can promote innovation diffusion, and then further proved that excellent market structure, favorable natural environment, excellent technological innovation, sound governance policies, and reasonable firm size have a positive impact on innovation diffusion. Lee [48] also draws a similar conclusion: when researchers can communicate with each other, spillover effect is more obvious, which effectively strengthens the maturity of scientific capacity, regional knowledge and scientific knowledge, promotes the integration of science and technology, and achieves effective innovative results. Xie [49] analyzed the worldwide data from 2007 to 2015 and concluded that international trade had an impact on innovation through information diffusion effect, firm competition effect and value chain optimization effect.

IDIT is driven by industrialization intention, spillover effect and industrialization assessment work together on industrialization intention [48], and the industrialization assessment composed of profit and product characteristics is the core determinant of industrialization. Because the cost of large-scale products will be thousands of times the laboratory samples, the external uneconomic will also increase (these costs can be defined as threshold for IDTI), so the firm will evaluate the feasibility of industrial production (willingness of IDTI compare with threshold).If the profit of the innovative industrial application is higher than the threshold, then the firm will carry out IDTI [45].

\subsection{Structure and Loops of ITI}

In summary, we have established the structure and loops of ITI. The structure of ITI is shown as Figure 1 and loops of ITI are shown as Table 1. 


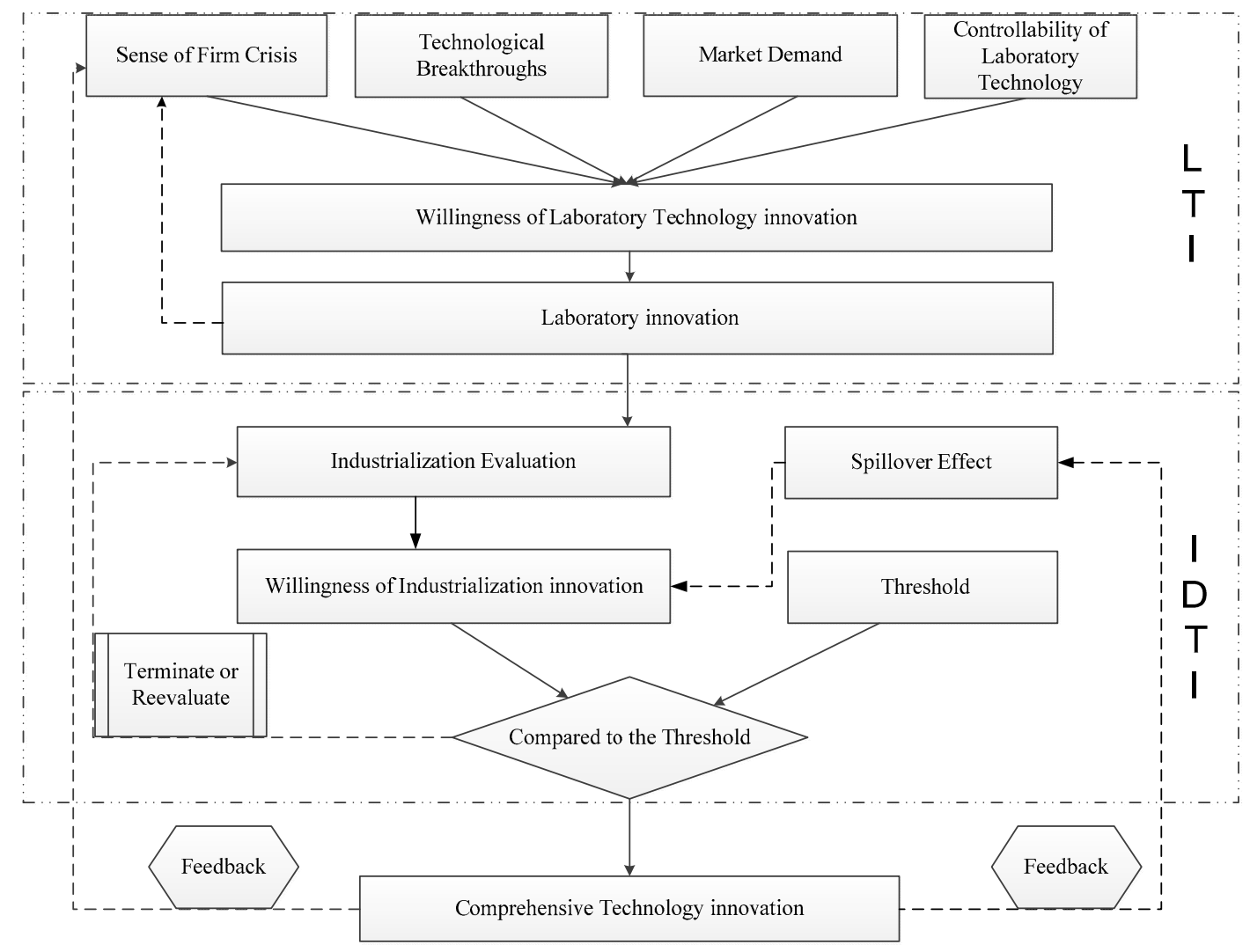

Figure 1. Structure of ITI.

Table 1. Loops of ITI.

\begin{tabular}{|c|c|}
\hline Category & Variables \\
\hline Forward Loop & $\begin{array}{l}\text { sense of firm crisis, etc.-willingness of LTI-Lab. innovation-Industrialization } \\
\text { evaluation-willingness of IDTI-ITI }\end{array}$ \\
\hline Feedback Loop1 & ITI—sense of firm crisis—Forward Loop—ITI \\
\hline Feedback Loop2 & ITI—Spillover effect—willingness of IDTI—ITI \\
\hline Feedback Loop3 & $\begin{array}{l}\text { Compared to the threshold-Industrialization evaluation-willingness of } \\
\text { IDTI-Compared to the threshold }\end{array}$ \\
\hline Feedback Loop4 & Lab. Innovation—sense of firm crisis, etc.-willingness of LTI-Lab. Innovation \\
\hline
\end{tabular}

\subsection{Simulation Model Formation}

\subsubsection{System Variables and Boundaries}

Systems engineering considers that most systems have boundaries. Extracting the main key variables, and finally determining the boundary of the model is the key to determine whether the system model is reasonable or not. In this study, the number of potential firm is taken as the starting variable. Based on the process of ITI from "non-upgrading" to "overall upgrading", the Bass [50] model and TOE [51] model are extended, and the impact of environmental factors is taken into account.

The names of three horizontal variables, i.e., the number of firm that have not been promoted by laboratory technology, the number of firm that have been finish the laboratory technology but not promoted industrial technology, and the number of firm that have been ITI. The corresponding two rates are "the rate of LTI" and "the rate of IDTI", and the introduction of "production". Industrial comparative advantage will affect the willingness of LTI, while technology spillover effect will affect 
the willingness of IDTI. Other Factors such as "perceived ease of use" and "perceived usefulness" are derived from TAM [52] model.

After screening, the key level variables are determined as "number of firm without laboratory technology innovation (NLTI)", "number of laboratory technology improvement \& unimproved industrialization (LTI\&UI)" and "number of firm with comprehensive technology innovation (TI)". The key rate variables are "laboratory technology innovation rate (LTIR)" and "industrialized technology innovation rate (IDR)". The key auxiliary variables are "laboratory technology innovation willingness (LTIW)", "industrialization willingness (IW)", "firm crisis feeling (FCF)", "CB (CB)", "cooperative firm coefficient (COOFC)" and "spillover effect (SE)". The key constants are "start threshold (ST)", "total number of firm (TNF)" and "technological breakthrough of scientific research units (TBASRU)".

\subsubsection{Simulation Model and Variables Code}

Based on the logical relationship of each variable, the system of ITI is constructed, as shown in Figure 2, together with the variables and the corresponding code are described in Table 2.

Table 2. Variables and Codes.

\begin{tabular}{|c|c|c|}
\hline Code & Variable & Reference \\
\hline NLTI & Number of firm without LTI & [50] \\
\hline LTI\&UI & Number of LTI improvement \& unimproved IDTI & [50] \\
\hline $\mathrm{TI}$ & Total ITI & [50] \\
\hline LTIR & LTI rate & [50] \\
\hline IDR & IDTI rate & [50] \\
\hline LTIW & LTI willingness & [50] \\
\hline IW & IDTI willingness & [50] \\
\hline FCF & Firm crisis feeling & [43] \\
\hline LTIC & LTI Controllability & [44] \\
\hline TBASRU & Technological breakthrough of scientific research units & {$[35,36]$} \\
\hline $\mathrm{D}$ & Demand & [37] \\
\hline FCFR & Firm communication frequency & [43] \\
\hline $\mathrm{CB}$ & communication barrier & [2] \\
\hline PCG & Product comparison gap & [37] \\
\hline SE & Spillover effect & [39] \\
\hline S & Spillover coefficient & [39] \\
\hline $\mathrm{COO}$ & Cooperative spillover strength & [39] \\
\hline $\mathrm{COM}$ & Competitive spillover intensity & [39] \\
\hline COOR & Cooperation firm ratio & [20] \\
\hline COMR & Competition firm ratio & [20] \\
\hline COOFC & Cooperative firm coefficient & [20] \\
\hline ITICR & ITI completion rate & [50] \\
\hline TNF & Total number of firm & [50] \\
\hline ST & Start threshold & [49] \\
\hline IF & Industrialization feasibility & [51] \\
\hline NP & New product industrialization evaluation & {$[50]$} \\
\hline $\mathrm{IPF}$ & Individual preference of firm & [22] \\
\hline IP & Industrial profit & [52] \\
\hline $\mathrm{C}$ & Cost & [52] \\
\hline $\mathrm{P}$ & Profit & [52] \\
\hline PUIT & Practical utility of industrial technology & {$[51]$} \\
\hline IU & Industrial usefulness & [51] \\
\hline RAP & Relative advantage of product & [51] \\
\hline IEU & Industrial ease of use & [51] \\
\hline $\mathrm{PO}$ & Product operability & [51] \\
\hline $\mathrm{TC}$ & Technical complexity & [51] \\
\hline SC & System compatibility & [51] \\
\hline FLC & Flow control & [51] \\
\hline
\end{tabular}




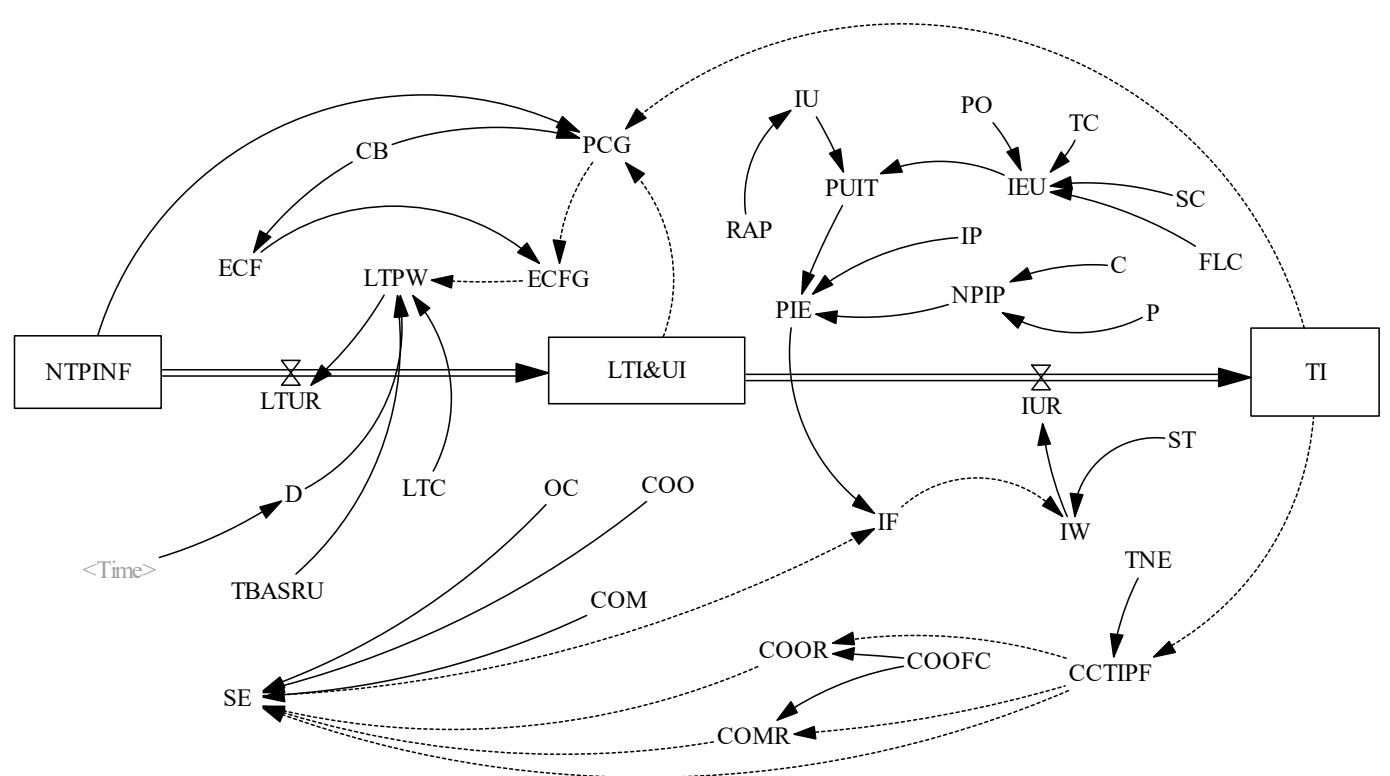

Figure 2. System of ITI.

\subsection{The Model Equation}

\subsubsection{Demand and LTI Willingness}

Demand (D) refers to the historical price and price adjustment of mobile phones, computers, and other products. Using the historical data [53] and on-site survey, this study defines the initial market demand as 0.1, with decay interval of 10 months and each time a $20 \%$ decline, as shown in Equation (1).

$$
\text { D = WITH LOOKUP (TIME, }([(0,0)-(60,1)],(0,0.1),(10,0.08),(20,0.06),(30,0.04),(40,0.02),(50,0)))
$$

After realizing the gap between firms, the firms will realize that if they do not innovate, they will be eliminated from the market, get bigger crisis feeling (FCF), so they will have greater willingness to innovate. Innovation will bring excess profits for a period of time, so firm will launch innovation to obtain greater profits. Technological breakthrough of scientific research units (TBASRU) is the strong foundation of firm innovation; Laboratory technology controllability (LTIC) refers to the ability to control innovation in the LTI stage, that is, the possibility of the initial intention turning into the final intention $[36,37,43,44]$. LTI willingness (LTIW) shown in Equation (2).

$$
\mathrm{LTIW}=(\mathrm{FCF}+\mathrm{D}+\mathrm{TBASRU}) \times \mathrm{LTIC}
$$

\subsubsection{IDTI Willingness}

The evaluation of the PUIT is complex and there is no stable and unified norm. In this study, based on TAM model, the PUIT can be decomposed into "industrial ease of use (IEU)" and "industrial usefulness (IU)" [27], as shown in Equation (3).

$$
\text { PUIT }=\text { IEU }+ \text { IU }
$$

Industrial usefulness (IU) is controlled by the relative advantage of products. Subtle advantages have no effects on usefulness, and only when the difference accumulates to a certain amount, then the difference of usefulness was appeared [27,51], as shown in Equation (4):

$$
\text { IU = WITH LOOKUP }(\operatorname{RAP},([(0,0)-(10,10)],(0,0),(0.25,0.2),(0.5,0.4),(0.75,0.6),(1,1))
$$


Heterogeneity is an important factor affecting firm development. Different corporate preferences will directly determine the attitude of firm to innovation, so firm with greater preference for innovation can obtain higher evaluation of industrialization. Higher availability of technology and higher profitability will further enhance the level of industrial assessment. In this study, the NP can be expressed as the arithmetic mean of PUIT, IPF and IP [27,48], as shown in Equation (5).

$$
\mathrm{NP}=(\mathrm{IPF}+\mathrm{PUIT}+\mathrm{IP}) / 3
$$

Industrialization feasibility refers to the initial feasibility of industrialization, which can be defined as the sum of industrialization assessment and spillover effects of new products, as shown in Equation (6); when the IF is greater than the starting threshold, the company has the willingness to carry out IDTI. In the study, the IDTI willingness (IW) is defined as the difference of the industrialization feasibility (IF) and the start threshold (ST), as shown in Equation (7).

$$
\begin{aligned}
& \mathrm{IF}=\mathrm{NP}+\mathrm{SE} \\
& \mathrm{IW}=\mathrm{IF}-\mathrm{ST}
\end{aligned}
$$

\subsubsection{Product Comparison Gap and Firm Crisis Feeling}

PCG depends on CB, because different levels of communication will directly affect the type and depth of information acquisitions [5,51], as well as the PCG shown in Equation (8).The FCFR is regulated by $\mathrm{CB}$, and higher $\mathrm{CB}$ reduce the frequency of communication between firms, where the FCFR shown in Equation (9). FCF is determined by the PCG and FCFR, more frequent communication and greater differences will bring a stronger sense of crisis, the FCF as shown in Equation (10).

$$
\begin{gathered}
\text { PCG = IF THEN ELSE }(\mathrm{CB} \leq 4,((((0.5 \times \text { “LTI\&UI” })+\mathrm{TI}) /(\mathrm{TI}+\text { “LTI\&UI” + NTLI }))), \\
((\mathrm{TI} /(\mathrm{TI}+\text { “LTI\&UI” }+\mathrm{NTLI})))) \\
\mathrm{FCFR}=1 / \mathrm{CB} \\
\mathrm{FCF}=\mathrm{FCFR} \times \mathrm{PCG}
\end{gathered}
$$

\subsubsection{Technology Spillover Effect}

Based on the impact of the environment in the TOE model on ITI, we consider that the spillover intensity will change between cooperation and competition in different environments. In this study, define the proportion of TI as an environmental variable [2,51], as shown in Equation (11).

$$
\begin{gathered}
\mathrm{SE}=\mathrm{IF} \text { THEN ELSE }(\mathrm{CCTIPF} \geq 0.5,((\mathrm{COOR} \times \mathrm{COO}+\mathrm{COMR} \times \mathrm{COM} / 2) \times \mathrm{ABS}(\mathrm{S})), \\
((\mathrm{COOR} \times \mathrm{COO} / 2+\mathrm{COMR} \times \mathrm{COM}) \times \mathrm{ABS}(\mathrm{S})))
\end{gathered}
$$

\subsubsection{Others}

LTI rate (LTIR) is defined as the lab innovation willingness (LTIW) multiply the number of firm without carry out LTI, as shown in Equation (12);Similar to this, IDTI rate (IDR), as shown in Equation (13).

$$
\begin{aligned}
& \text { LTIR }=\text { LTIW } \times \text { NTLI } \\
& \text { IDR }=\text { “LTI\&UI” } \times \text { IW }
\end{aligned}
$$

Cooperation firm ratio (COOR) defined as the product of the ratio of completed innovation companies to the coefficient of cooperative firm (COOEC), as shown in Equation (14). Similar to this, Competition firm ratio (COMR), as shown in Equation (15).

$$
\mathrm{COOR}=\mathrm{COOFC} \times \mathrm{ITICR}
$$




$$
\mathrm{COMR}=\mathrm{ITICR} \times(1-\mathrm{COOFC})
$$

ITI completion rate (ITICR) defined as the quotient of Total ITI (TI) and the Total number of firm (TNF), as shown in Equation (16).

$$
\text { ITICR }=\mathrm{TI} / \mathrm{TNF}
$$

Number of firm without LTI (NTLI) defined as the total number of firm (TNF) and the difference between the subtracted LTI rate (LTIR), as shown in Equation (17). Similar to this, number of LTI improvement \& unimproved IDTI (LTI\&UI) shown in Equation (18), and Total ITI (TI) shown in Equation (19).

$$
\begin{aligned}
\text { NTLI } & =\text { INTEG }(- \text { LTIR, TNF }) \\
\text { LTI\&UI } & =\text { INTEG }(\text { LTIR }- \text { IDR, } 0) \\
\text { TI } & =\text { INTEG }(\text { IDR, } 0)
\end{aligned}
$$

\section{Data and Model Testing}

\subsection{Date}

In this study, Vensim PLE software is used for simulation. INITIAL TIME = 0; FINAL TIME = 60; TIME STEP = 0.125; TIME UNIT: Month. This study uses Delphi method to assign the values. The specific values are shown in Table 3.

Table 3. Setting of the Parameters.

\begin{tabular}{cccc}
\hline Variable & Value & Foundation & Date \\
\hline TBASRU & 0.136 & Outstanding Youth Science Foundation passing rate & China Statistical Yearbook [53] \\
ST & 0.112 & 1.5 times the loan interest rate & China Statistical Yearbook [53] \\
LTC & 0.33 & The National Natural Science Foundation of China passing rate & China Statistical Yearbook [53] \\
RAP & 0.135 & Delphi Method & Expert Groups and Surveys \\
SC & 0.679 & Delphi Method & Expert Groups and Surveys \\
FLC & 0.369 & Delphi Method & Expert Groups and Surveys \\
PO & 0.579 & Delphi Method & Expert Groups and Surveys \\
TC & 0.236 & Proportion of invention patents & China Statistical Yearbook [53] \\
P & 0.3 & Four times the rate of inflation & China Statistical Yearbook [53] \\
C & 0.15 & Two times the rate of inflation & Expert Groups and Surveys \\
IP & 0.156 & Delphi Method & Expert Groups and Surveys \\
OC & 0.3 & Delphi Method & Expert Groups and Surveys \\
COO & 0.3 & Delphi Method & Expert Groups and Surveys \\
COM & 0.1 & Delphi Method & Expert Groups and Surveys \\
COOEC & 0.3 & Delphi Method & Expert Groups and Surveys \\
TNE & 3000 & Delphi Method & Stanley Milgram [54] \\
CB & 6 & Six Degrees of Separation & \\
\hline
\end{tabular}

\subsection{Model Testing}

Before running the model, the fitting degree between the model and the real world and the stability of the model should be verified. This test is divided into two steps: output fitting of historical data and Sensitivity testing.

\subsubsection{Output Fitting of Historical Data}

We manually investigated the application of biometrics in the top seven smartphone brands (accounting for $99 \%$ of China's market share) [55]. After the first company announced the start of research and development of biometric technology, the time span for the first application of this technology in different firm was 6, 13, 18, 21, 27, 32 and 36 months, respectively. Based on this, the simulated value is compared with the real value (Figure 3). The simulated value and the real value are highly consistent in the image. The Pearson correlation coefficient of the two groups of data is 0.975 , 
and the fitting degree of the simulated value and the real value is 0.958 . It shows that the model has a strong ability to interpret the real world.

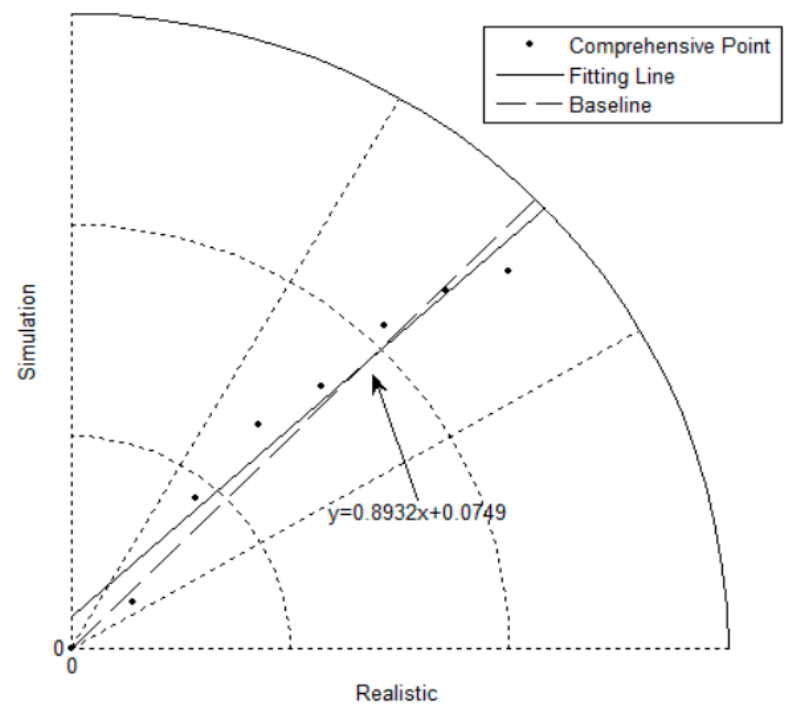

Figure 3. Realistic and Simulation.

\subsubsection{Sensitivity Testing}

Then the robustness of the model is discussed by sensitivity analysis. It is generally believed that the change of a certain quantity in the model will bring about some changes in the output results of the model, but the general trend will not change, and the output results will change in a controllable range. If a certain value is changed, the output of the model changes uncontrollably and subversively, then the model is viewed to be sensitive, and there are many limitations when it is applied to the real world without assuming conditions. In this study, sensitivity analysis is carried out by changing the breakthrough ability of scientific research institutions. The breakthrough ability of scientific research units is set to F1 $=0.1, \mathrm{~F} 2=0.3$ and F3 $=0.5$. The changes of "two firm number", "two wishes" and "two rates" in the model are observed. The specific output is shown in Figures 4-6.

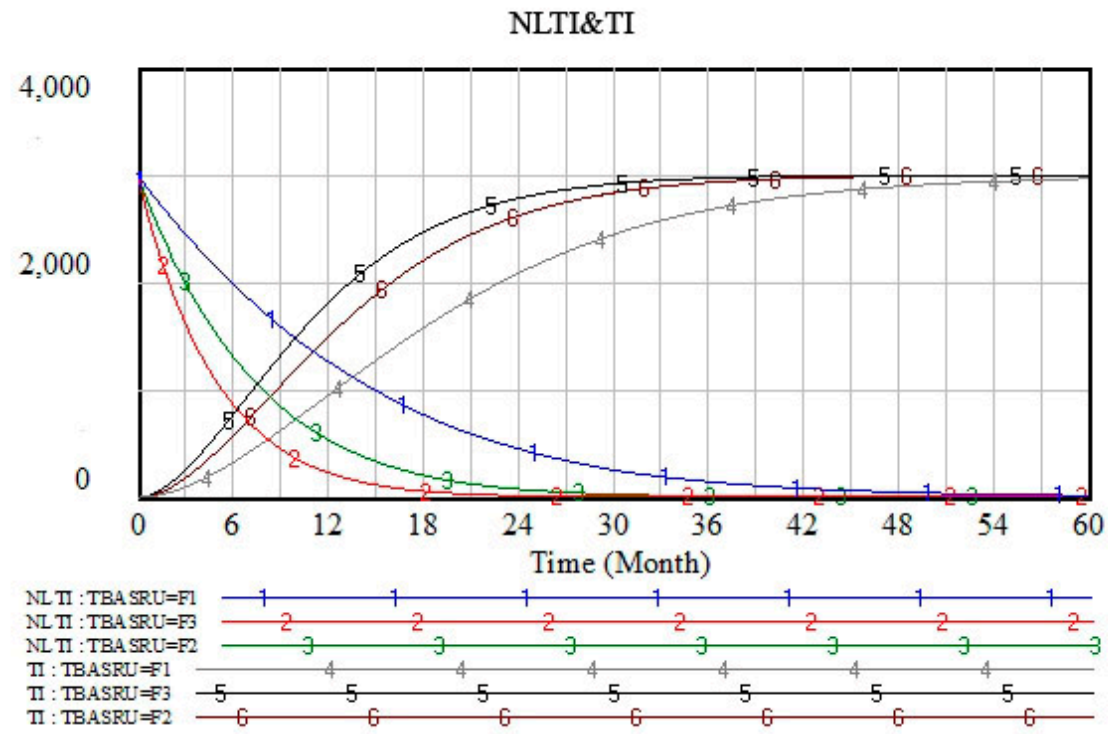

Figure 4. Comparison of the Two Types of Firms. 


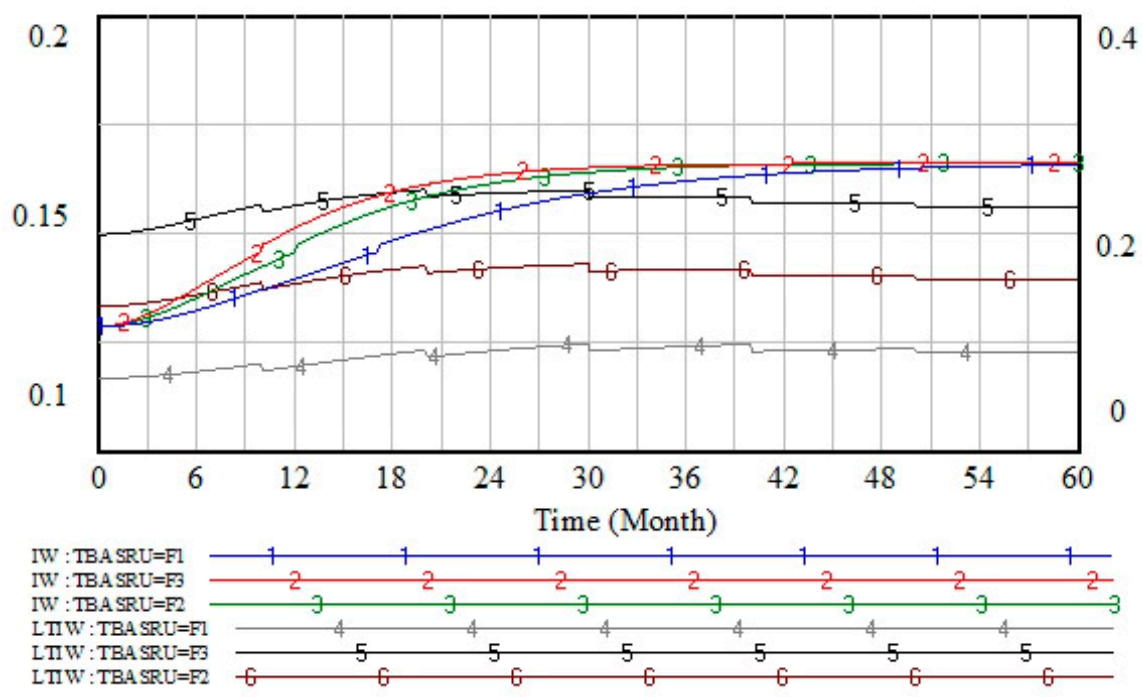

Figure 5. Comparison of Two Willingness.

IDR

LTIR

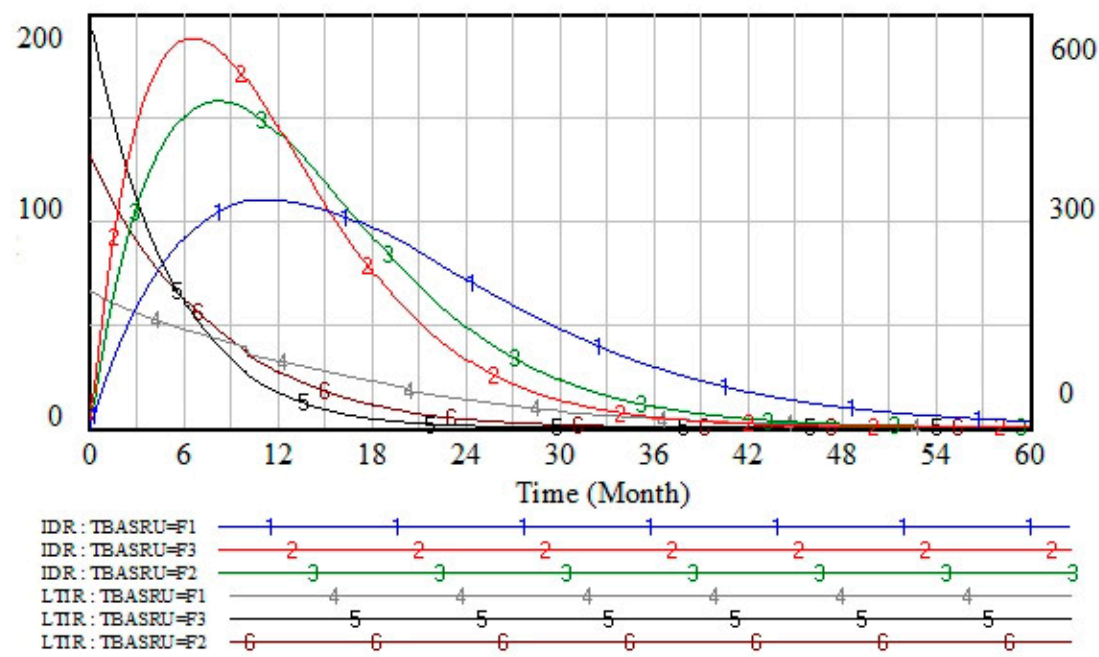

Figure 6. Comparison of Two Rates.

As shown in Figures 4-6, after changing the TBASRU, the key horizontal variables, key rate variables and auxiliary variables in the model did not change uncontrollably or subversively but fluctuated in amplitude and rate. We can conclude that the ITI model is insensitive to parameters and has certain guiding significance for the real world.

\section{System Simulation and Results}

\subsection{Simulation and Results of SE}

In the firm information network, there may be two directions of information transmission. The first is that the firm receives external information, and the second is that the firm sends information to the outside. According to the different direction of SE, it is assigned and the simulation results are observed. If a firm accepts external spillover radiation, it can be considered that the SE is greater than 0 ; on the contrary, the SE is less than 0 . Specific assignments, as shown in Table 4: 
Table 4. SE Coefficient Assignment Table (1).

\begin{tabular}{ccccc}
\hline Code & S1 & S2 & S3 & S4 \\
\hline assignment & 0.2 & 0.5 & -0.2 & -0.5 \\
\hline
\end{tabular}

As shown in Figure 7, curves 1 and 3 coincide with curves 2 and 4 completely, which shows that in the firm network, the radiation effect (including external radiation and internal radiation) of the firm has the same effect on the enhancement of ITI when the absolute value of SE coefficient is the same. Then the SE is assigned as shown in Table 5.

TI
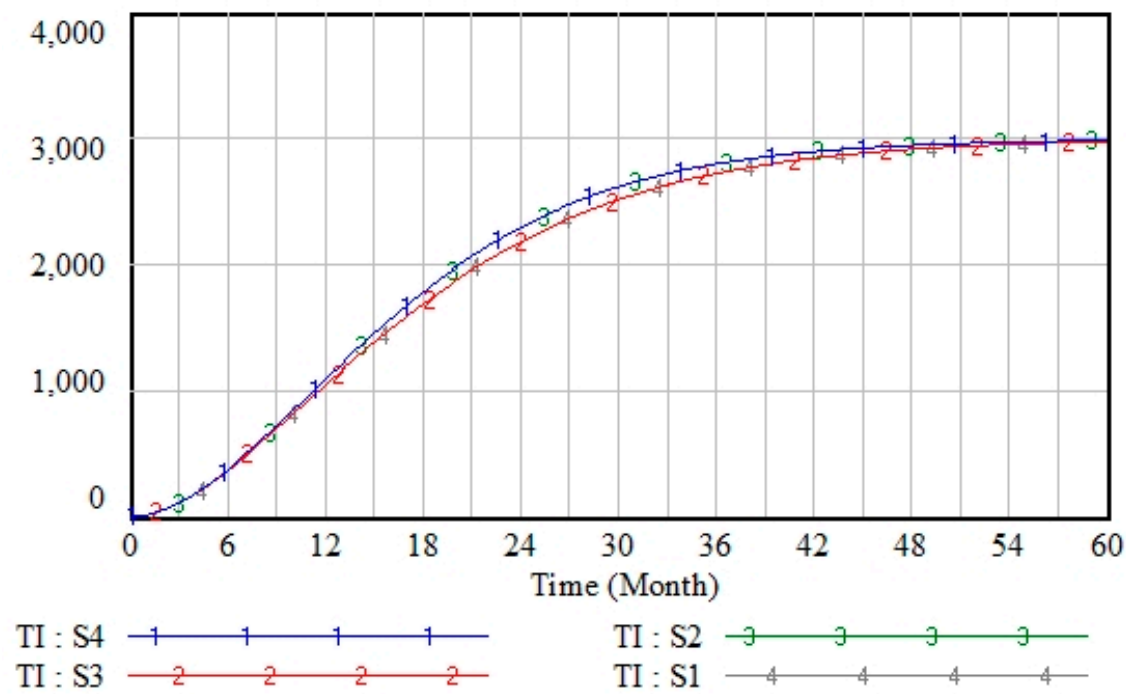

Figure 7. TI Under the SE.

Table 5. SE Coefficient Assignment Table (2).

\begin{tabular}{ccccc}
\hline Code & S5 & S6 & S7 & S8 \\
\hline assignment & 0.1 & 0.25 & 0.4 & 0.55 \\
\hline
\end{tabular}

As shown in Figure 8a,b, there is no significant difference in IDR in the first few months. With time going by, the SE on the rate of ITI began to appear. The SE coefficient increasing will make IDR steeper, which can improve the IDR and enhance the process of ITI. This is confirmed by the number of firm that has improved their technology in an all-around way. The time of $S 8$ is nearly $11 \%$ higher than that of S5.

Figure $8 \mathrm{c}$ shows that the environment has a significant impact on SE. All the curves are in the period of $15 \mathrm{M}-18 \mathrm{M}$. Faults and jumps have occurred. Because have been upgraded to be the main body in an all-around way. The quality and amount of information acquired by firms will increase, which will lead to the change of spillover intensity. It can be concluded that the SE can effectively improve the process of ITI. 

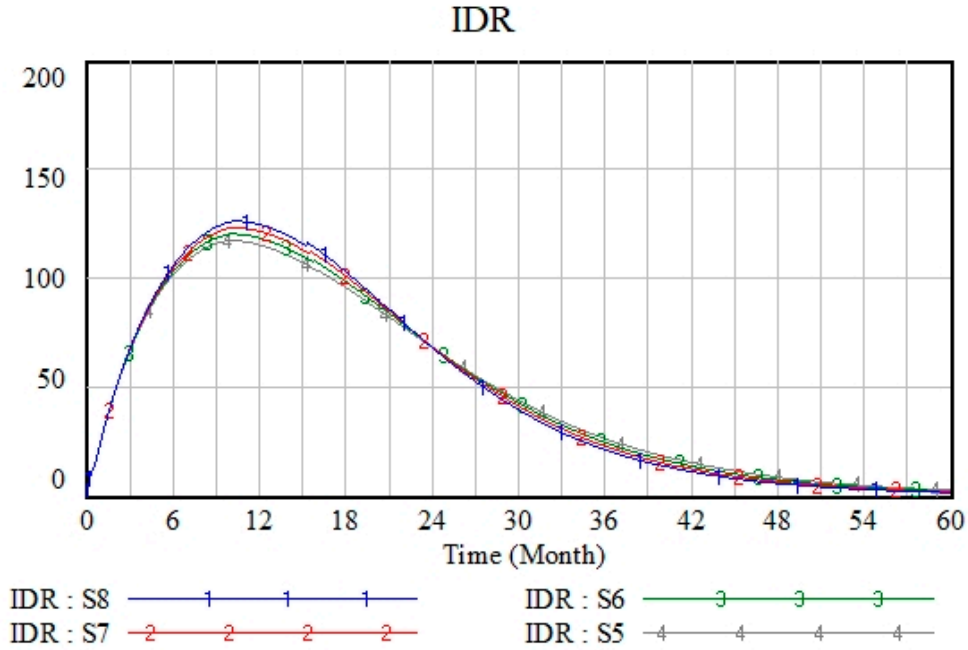

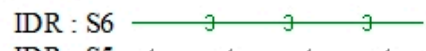

(a)

TI

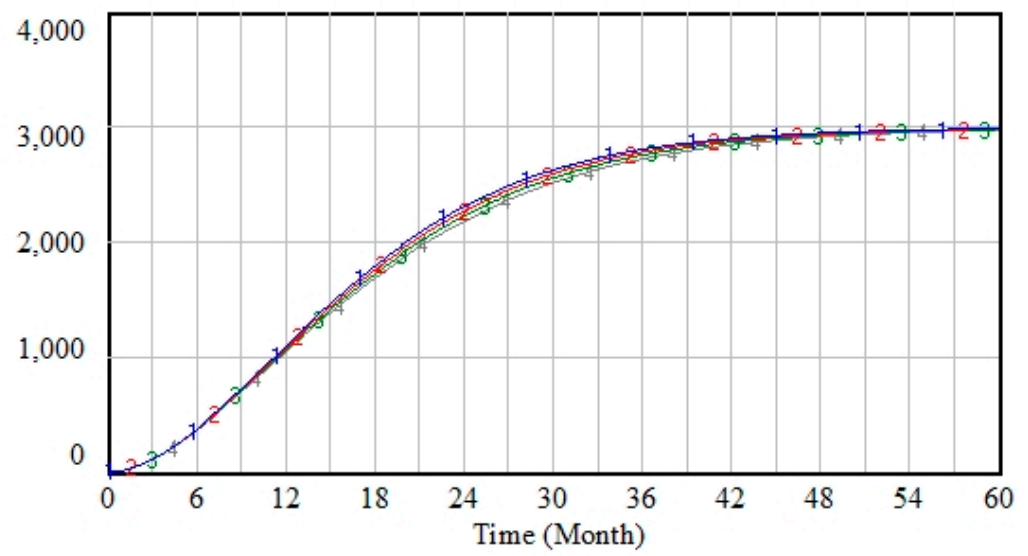

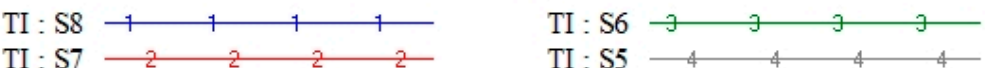

(b)

SE

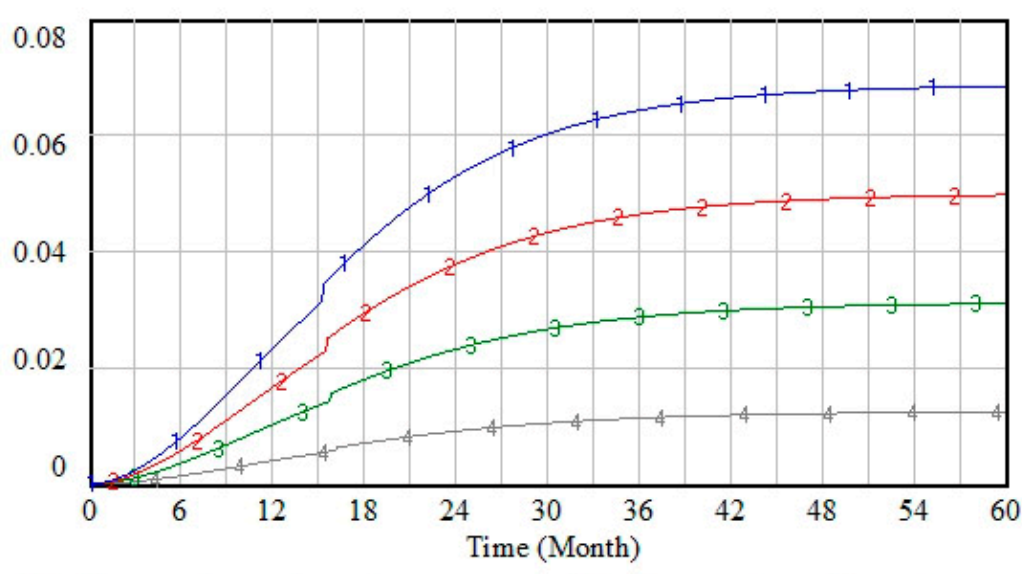

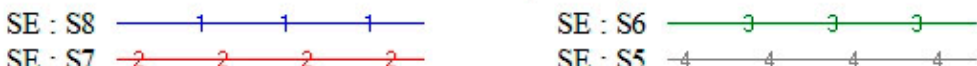

(c)

Figure 8. (a) Change of IDR; (b) Change of TI; (c) Change of SE. 


\subsection{Simulation and Results of $C B$}

Another key framework within cooperation and innovative is $\mathrm{CB}$. The range of $\mathrm{CB}$ is from 1 to infinite, and the corresponding information transmission efficiency is from 1 to 0 . In particular, in order to facilitate our simulation of infinite barriers, we define $C B=10,000$. Because when $C B=10,000$, the information transmission capacity is 0.00001 , which is very close to the target of complete barrier. This part simulates the conduction efficiency represented by different $\mathrm{CB}$ and takes the corresponding values of CB as 1, 3, 6, 9 and 10,000. Among them, value 1 represents the complete transmission of information, and there is no hindrance to the transmission of information; value 10,000 means that information is not transmitted at all, and firms cannot get the sense of crisis through the information network. The image (Figure 9) is as follows:

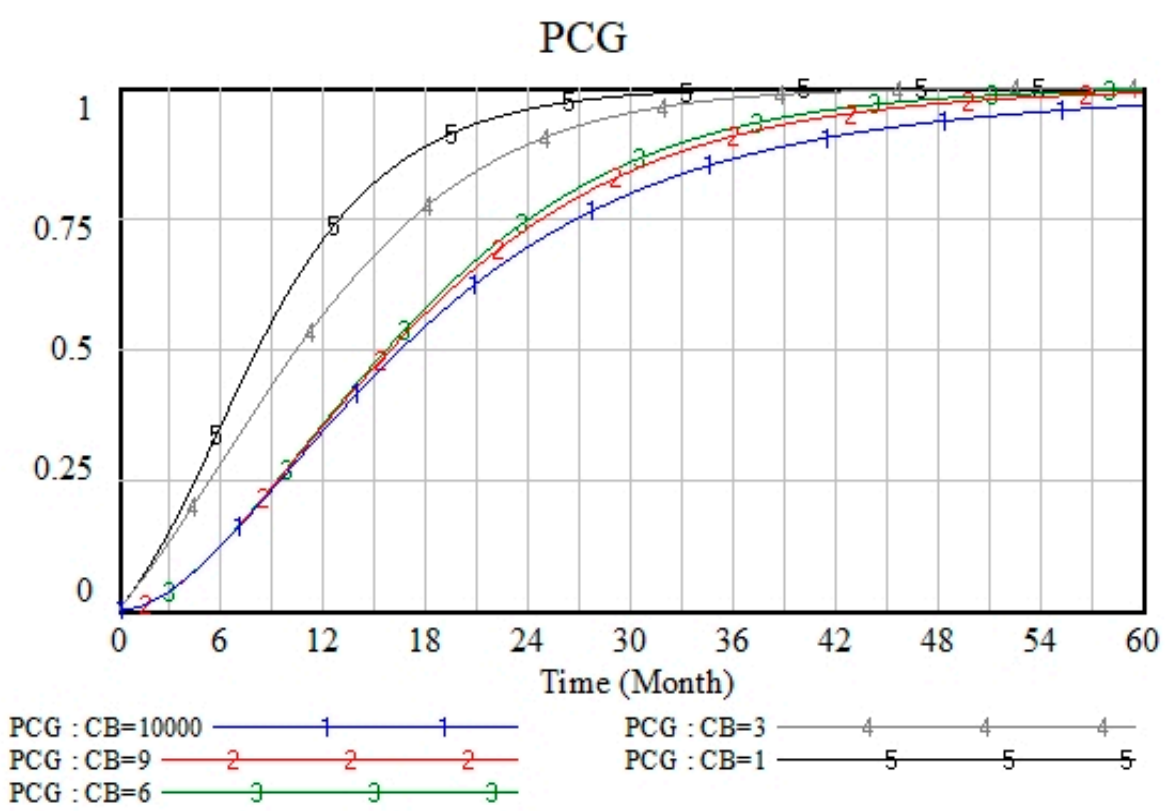

(a)

LTIR

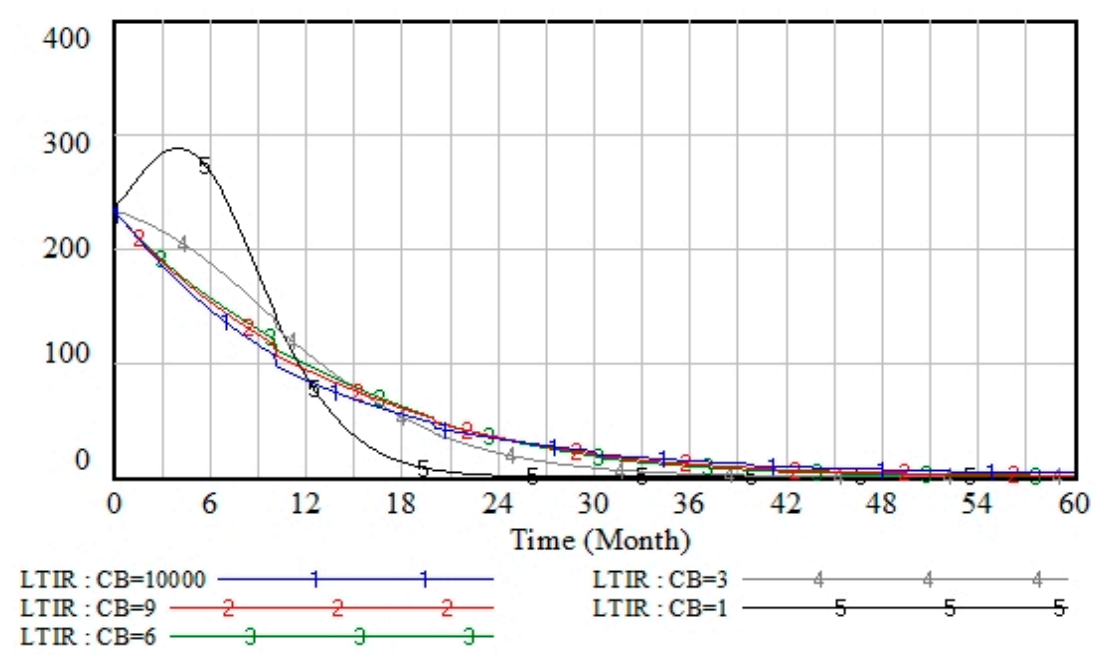

(b)

Figure 9. Cont. 


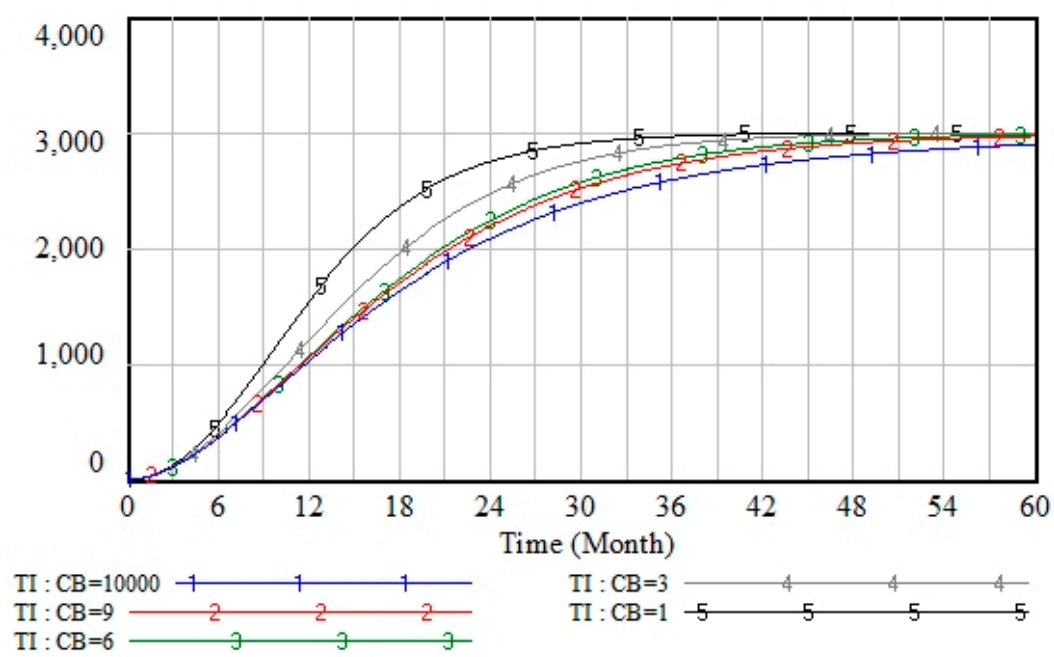

(c)

Figure 9. (a) Change of PCG; (b) Change of LTIR, (c) Change of TI.

As Figure 9a, the curve can be divided into two groups. The shape of the first group (curve $1,2,3$ ) is similar, while the second group (curve 4,5 ) is significantly different from the first group. Fundamentally, the level of CB affects the level of information acquired by firm. Under the lower CB, firm will get some information with a higher level of privacy (firm carry out laboratory experiments, etc.), while under the higher $\mathrm{CB}$, firm cannot get such information. In other cases, under the same conditions, the richer information levels lead to changes in the image.

From Figure 9b, we can see that the change of CB will result in a great change in the LTIR, especially in the case of without barriers (as curve 5 shown). This is because when CB are low and information exchange efficiency is very high, firm's sense of crisis will rise rapidly, which will lead to various firm to carry out LTI in the short term. Subsequently, due to the limitation of the total number of firm, the LTIR began to decline significantly, while the small shocks caused by other factors were also weakened in the process. Eventually, in the initial stage, the LTIR increased rapidly, and then the curve began to decline rapidly. On the contrary, the other curves (as curves 2, 3, 4 shown) are the monotonous decreasing trend, and the short-term shocks caused by changes in demand are also clearly visible. It can be concluded that reducing barriers to communication can effectively improve the rate of LTI.

The impact of CB on the TI can be reflected in the curve, i.e., its slope. As shown in Figure 9c, the trend of the curves in the graph is basically the same, and all the curves are monotonous upward curves. The lower the $\mathrm{CB}$, the fewer firm will be able to improve their technology in an all-round way at the same time. Under the complete barrier and non-barrier conditions, the speed of ITI will decrease by $76.5 \%$. Therefore, CB have a tremendous impact on the rate of ITI.

\section{Conclusions and Suggestions}

\subsection{Conclusions}

Because there is no systematic description of the process of ITI, and there is not much research on the communication barrier and spillover effect. In order to remedy this deficiency, through a system dynamics model of ITI, the study simulates the path of ITI and analyses the regulatory communication barrier and spillover effect on ITI. The results show that: (1) SE has a significant impact on ITI in various radiation directions, and deeper exchanges and cooperation between firm should be encouraged. With different SE, the completion rate of ITI improvement in simulation increase by $11 \%$. (2) CB plays an important role in regulating ITI, and lower CB can effectively enhance the process of ITI. 
CB transmission not only accelerates the LTIR but also shortens the time to complete the overall ITI. Even under different size of $\mathrm{CB}$, the ITI improvement in the simulation experiment increased by $76.5 \%$.

\subsection{Suggestions}

At the institutional level, we should improve the top-level design, promote cooperation between firms and establish appropriate industrial agglomeration areas. The cooperation between firms is not simply the capital input of lagging firm by advantageous firm, nor the investment of large amounts of resources into departments with low production efficiency. At the same time, we should increase investment in R\&D and change the economic development model of labor-intensive industries. Because core technology cannot be obtained from other firm, it can only be obtained through independent research and development, so in order to enhance the status of the international value chain, we must adhere to the principle of "innovation-driven", and enhance scientific research to break through the bottleneck of transformation of scientific research achievements.

At the market level, we should promote market-oriented development, make use of the advantages of market resource allocation, promote benign cooperation among firm, and prevent malignant competition among firms. There is still a certain gap between developing countries scientific research and the developed countries in the world. For the market, it is necessary to guide capital into $R \& D$ units of science and technology, which can greatly enhance the ability of scientific research organizations, meanwhile increase applied research and innovative research projects. We should introduce market mechanisms to promote cooperation among scientific research institutions such as universities, encourage cooperation across regions and industries, and support exploratory cooperation. We also should establish a high-tech market, and improve the supervision and testing system of firms' innovative achievements, promoting the landing of scientific research achievements, and give full play to the role of scientific research institutions in promoting the surrounding areas.

At the government level, a complete information exchange network should be established. In recent years, with the rapid development of infrastructure construction in China, the efficiency of information exchange has been further improved, but there is still a big gap compared with the advanced level in the world. We should reduce CB and actively develop technical cooperation, in order to promote win-win cooperation among enterprises and prevent waste of resources. In order to change the current situation of slow infrastructure construction in China, we should not rush for quick success and instant benefit in infrastructure construction. We should take into account the bearing capacity of the region in the future and reserve the necessary space for future expansion, and give full play to the regulatory role of information communication and promote innovation.

Author Contributions: Data curation, B.G.; Formal analysis, J.G.; Funding acquisition, J.X. and B.Y.; Methodology, J.G.; Project administration, J.X.; Resources, B.Y.; Software, J.G.; Validation, X.S.; Visualization, J.G., B.G. and X.S.; Writing-original draft, J.G.; Writing—review \& editing, B.G. and X.S.

Funding: This research was funded by Ministry of Education Humanities and Social Sciences Research Project (19YJC630178); Project of National Natural Science Foundation of China (71502050); Henan Philosophy and Social Sciences Planning Project (2018CJJ080); General Project of Humanities and Social Sciences of Henan Education Department (2019-ZZJH-043); Key Scientific Research Projects of Henan Higher Education Institutions (17A630022); The Fundamental Research Funds for the Universities of Henan Province (SKJYB2016-07).

Conflicts of Interest: The authors declare no conflict of interest.

\section{References}

1. Loke, B. China's economic slowdown: Implications for Beijing's institutional power and global governance role. Pac. Rev. 2018, 31, 673-691. [CrossRef]

2. Liu, C.; Guo, Q. Technology Spillover Effect in China: The Spatiotemporal Evolution and Its Drivers. Sustainability 2019, 11, 1694. [CrossRef]

3. Feng, T.; Sun, L.; Zhang, Y. The relationship between energy consumption structure, economic structure and energy intensity in China. Energy Policy 2009, 37, 5475-5483. [CrossRef] 
4. Ramaswami, A.; Jiang, D.; Tong, K.; Zhao, J. Impact of the Economic Structure of Cities on Urban Scaling Factors: Implications for Urban Material and Energy Flows in China. J. Ind. Ecol. 2017, 79, 16115. [CrossRef]

5. Dong, J.; Xu, Y.; Hwang, B.G.; Ren, R.; Chen, Z. The Impact of Underground Logistics System on Urban Sustainable Development: A System Dynamics Approach. Sustainability 2019, 11, 1223. [CrossRef]

6. Zheng, J.H.; Song, J.; Zhang, Y.C.; Zheng, Y.; Jiang, Q.K. The Evaluation of Conversion of New and Old Driving Force of China's Economic Growth. China Ind. Econ. 2018, 6, 24-42.

7. Du, M.; Wang, B.; Zhang, N. National research funding and energy efficiency: Evidence from the National Science Foundation of China. Energy Policy 2018, 120, 335-346. [CrossRef]

8. Harrison, R.; Scheela, W.; Lai, P.C.; Vivekarajah, S. Beyond institutional voids and the middle-income trap: The emerging business angel market in Malaysia. Asia Pac. J. Manag. 2017, 35, 965-991. [CrossRef]

9. Lingliang, Z. Conceptual Analysis of China's Belt and Road Initiative: A Road towards a Regional Community of Common Destiny. Chin. J. Int. Law 2016, 15, 21. [CrossRef]

10. Liu, S.X. Innovation Design: Made in China 2025. Des. Manag. Rev. 2016, 27, 52-58.

11. Singh, R.; O'Hagan, F. "Apping Up": Prospects for Information Technology Innovation in Return to Work Communication. J. Occup. Rehabil. 2018, 29, 104-118. [CrossRef]

12. Choi, S.; Noh, M.S.; Yoon, J.; Park, H.; Seo, W. Analyzing Technological Spillover Effects between Technology Classes: The Case of Korea Technology Finance Corporation. IEEE Access 2018, 6, 3573-3584. [CrossRef]

13. Grupp, H. Spillover effects and the science base of innovations reconsidered: An empirical approach. J. Evol. Econ. 1996, 6, 175-197. [CrossRef]

14. Srholec, M. Understanding the diversity of cooperation on innovation across countries: Multilevel evidence from Europe. Pap. Innov. Stud. 2015, 24, 159-182. [CrossRef]

15. Liu, X.; Buck, T. Innovation performance and channels for international technology spillovers: Evidence from Chinese high-tech industries. Res. Policy 2007, 36, 355-366. [CrossRef]

16. Weber, B.; Heidenreich, S. Improving innovation capabilities by cooperation: Examining effects of core network management functions and relational mechanisms in the industrial goods sector. Int. J. Innov. Manag. 2016, 20, 1650074. [CrossRef]

17. Stejskal, J.; Meričková, B.M.; Prokop, V. The cooperation between enterprises: Significant part of the innovation process-A case study of the czech machinery industry. E M Èkon. Manag. 2016, 19, 110-122. [CrossRef]

18. Tigabu, A.D.; Berkhout, F.; Van Beukering, P. Technology innovation systems and technology diffusion: Adoption of bio-digestion in an emerging innovation system in Rwanda. Technol. Forecast. Soc. Chang. 2015, 90, 318-330. [CrossRef]

19. Wei, S.; Yong, Z. Compulsory Technology Transfer, Adptive Ripening and Innovation Spillover Effect-From China Industry's Empirical Evidence. Soft Sci. 2019, 33, 52-55. (In Chinese)

20. Radicic, D.; Douglas, D.; Pugh, G.; Jackson, I. Cooperation for innovation and its impact on technological and non-technological innovation: Empirical evidence from European SMEs in traditional manufacturing industries. Int. J. Innov. Manag. 2019, 23, 1-41. [CrossRef]

21. Kang, J.H.; Lee, J.S.; Jang, D.S.; Park, S.S. A Methodology of Partner Selection for Sustainable Industry-University Cooperation Based on LDA Topic Model. Sustainability 2019, 11, 3478. [CrossRef]

22. Nave, A.; Franco, M. University-Firm cooperation as a way to promote sustainability practices: A sustainable entrepreneurship perspective. J. Clean. Prod. 2019, 230, 1188-1196. [CrossRef]

23. De Moraes Silva, D.R.; Furtado, A.T.; Vonortas, N.S. University-industry R\&D cooperation in Brazil: A sectoral approach. J. Technol. Transf. 2018, 43, 1-31.

24. Liping, W.; Huiming, L. Organization Distance, Value Co-Creation, and Industry-University-Research Collaborative Innovation Performance. Chin. J. Manag. 2019, 5, 704-711.

25. Forrester, J.W. Industrial Dynamics; MIT Press: Cambridge, MA, USA, 1961; p. 11.

26. Hayward, J.; Roach, P.A. Newton's laws as an interpretive framework in system dynamics. Syst. Dyn. Rev. 2018, 33, 183-218. [CrossRef]

27. Ding, Z.; Zhu, M.; Tam, V.W.; Yi, G.; Tran, C.N. A system dynamics-based environmental benefit assessment model of construction waste reduction management at the design and construction stages. J. Clean. Prod. 2018, 176, 676-692. [CrossRef] 
28. Biondi, G.; Onori, R.; Volpetti, C.; Carlini, C.; Tsaples, G.; Armenia, S. A system dynamics simulation tool for the management of extreme events in urban transportation systems. Int. J. Crit. Infrastruct. 2018, 13, 329. [CrossRef]

29. Xu, T.; Birchfield, A.B.; Overbye, T.J. Modeling, Tuning, and Validating System Dynamics in Synthetic Electric Grids. IEEE Trans. Power Syst. 2018, 33, 6501-6509. [CrossRef]

30. Tunzelmann, N.V.; Wang, Q. An evolutionary view of dynamic capabilities. Manag. Acc. Res. 2003, 6, 47-62.

31. Tunzelmann, N.V.; Wang, Q. Capabilities and production theory. Struct. Chang. Econ. Dyn. 2007, 18, $192-211$. [CrossRef]

32. Rapp, F. Analytical Philosophy of Technology; Springer: Berlin, The Netherlands, 1985; pp. 77-78.

33. Winter, S. Knowledge and Competence as Strategic Assets. Strateg. Manag. Int. Cap. 1998, 10, $165-187$.

34. Bo, C.; Eliasson, G. The Nature and Importance of Economic Competence. Ind. Corp. Chang. 1991, 3, 687-711.

35. Martínez-Román, J.A.; Romero, I. Determinants of innovativeness in SMEs: Disentangling core innovation and technology adoption capabilities. Rev. Manag. Sci. 2017, 11, 1-27. [CrossRef]

36. Broekel, T.; Rogge, N.; Brenner, T. The innovation efficiency of German regions-A shared-input DEA approach. Rev. Reg. Res. 2018, 38, 77-109. [CrossRef]

37. Lee, H.; Cha, S.; Park, H. The effect of technology-exploration on product innovation: An analysis based on Korean manufacturing SMEs. Int. J. Qual. Innov. 2016, 2, 285. [CrossRef]

38. Zoia, M.G.; Barbieri, L.; Cortelezzi, F.; Marseguerra, G. The determinants of Italian firms' technological competencies and capabilities. Eurasian Bus. Rev. 2018, 8, 453-476. [CrossRef]

39. Fang, C.; Ma, H.; Wang, Z.; Li, G. The sustainable development of innovative cities in China: Comprehensive assessment and future configuration. J. Geogr. Sci. 2014, 24, 1095-1114. [CrossRef]

40. Kalapouti, K.; Petridis, K.; Malesios, C.; Dey, P.K. Measuring efficiency of innovation using combined Data Envelopment Analysis and Structural Equation Modeling: Empirical study in EU regions. Ann. Oper. Res. 2017, 1-24. [CrossRef]

41. Miao, Y.; Song, J.; Lee, K.; Jin, C. Technological catch-up by east Asian firms: Trends, issues, and future research agenda. Asia Pac. J. Manag. 2018, 35, 639-669. [CrossRef]

42. Rieu, A.M. Innovation today: The Triple Helix and research diversity. Triple Helix 2014, 1, 237. [CrossRef]

43. Rosenzweig, S. The effects of diversified technology and country knowledge on the impact of technological innovation. J. Technol. Transf. 2017, 42, 564-584. [CrossRef]

44. Lee, C.Y.; Lee, J.H.; Gaur, A.S. Are large business groups conducive to industry innovation? The moderating role of technological appropriability. Asia Pac. J. Manag. 2017, 34, 1-25. [CrossRef]

45. Wang, R.H.; Lv, Y.B.; Duan, M. Evolutionary game of inter-firm knowledge sharing in innovation cluster. Evol. Syst. 2016, 8, 121-133. [CrossRef]

46. Alba, M.F.; Mas-Verdú, F. New firm creation and innovation: Industrial patterns and inter-sectoral linkages. Int. Entrep. Manag. J. 2013, 9, 501-519. [CrossRef]

47. Zhou, G. An Empirical Study of the Technological Innovation Cooperation Performance between the Resource-Based Enterprises; Springer: Berlin/Heidelberg, Germany, 2014; pp. 1207-1218.

48. Lee, C.; Park, G.; Kang, J. The impact of convergence between science and technology on innovation. J. Technol. Transf. 2016, 43, 522-544. [CrossRef]

49. Xie, L.; Wang, S. The effect of domestic and foreign trade coordination on technological innovation: Complements or substitutes? Front. Bus. Res. China 2017, 11, 14. [CrossRef]

50. Bass, F.M. A New Product Growth for Model Customer Durables. Manag. Sci. 1969, 5, 215-227. [CrossRef]

51. Zhu, K.; Kraemer, K.L.; Xu, S.; Dedrick, J. Information technology payoff in e-business environments: An international perspective on value creation of e-business in the financial services industry. J. Manag. Inform. Syst. 2004, 1, 17-54. [CrossRef]

52. Davis, F.D. User Acceptance of Information Technology:System Characteristics, User Perceptions and Behavioral Impacts. Int. J. Man Mach. Stud. 1993, 3, 475-487. [CrossRef]

53. China Statistical Yearbook (1981-2018). Available online: http://data.cnki.net/Yearbook/Single/ \%20N2018110025 (accessed on 20 May 2019). (In Chinese). 
54. Kiermer, V. Six degrees of separation. Nat. Methods 2006, 3, 964. [CrossRef]

55. JIGUANG Smart Phone Industry Research Report. Available online: https://doc.mbalib.com/view/ 5bc89c03945c8911ca99578df80c3f05.html (accessed on 12 May 2019). (In Chinese).

(C) 2019 by the authors. Licensee MDPI, Basel, Switzerland. This article is an open access article distributed under the terms and conditions of the Creative Commons Attribution (CC BY) license (http://creativecommons.org/licenses/by/4.0/). 